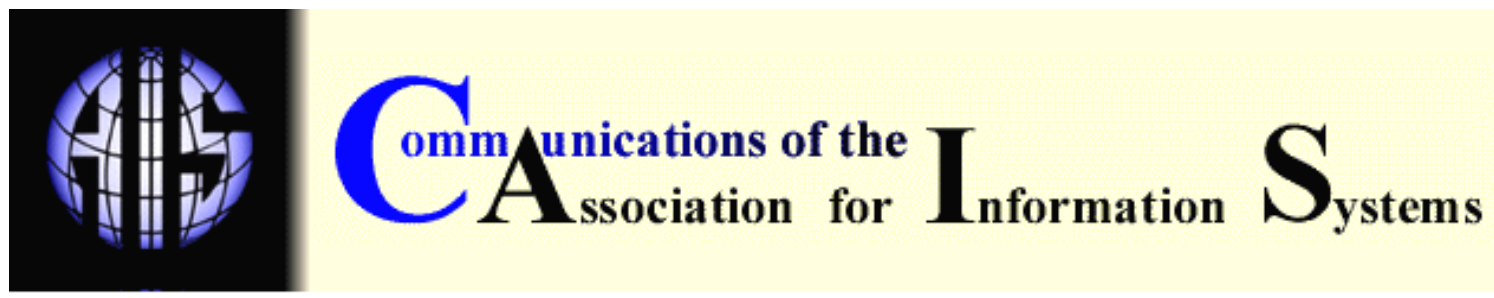

\title{
FLOW IN COMPUTER-MEDIATED ENVIRONMENTS: PROMISES AND CHALLENGES
}

Christina M. Finneran

Ping Zhang

School of Information Studies

Syracuse University

cmfinner@syr.edu

\begin{abstract}
This paper provides a critical review to analyze the promises and important challenges of studying flow, a psychological state, in the computer-mediated environments (CME). Despite the strong interest in IS, $\mathrm{HCl}$, Marketing, Education, and other research disciplines over more than a decade, adapting the phenomenon of flow to computer users shows high inconsistencies and discrepancies in the literature. In addition, few studies attempt to provide a coherent picture of the area. Based on a careful examination of the literature, we identify both conceptual and methodological challenges faced when studying flow in CME. Although not all challenges are resolved, we point out directions and possible solutions for some challenges and call for more studies in this promising area. The paper further discusses implications for research in human computing behavior in general and in flow in particular. It cautions researchers to examine hidden assumptions of theories in other disciplines before applying them to address IT related issues and concerns.
\end{abstract}

Keywords: Flow, holistic experience with IT, computer-mediated environment, human-computer interaction

\section{INTRODUCTION}

Flow or optimal experiences, colloquially referred to as "the zone" in sports, are the topic of much study by the psychologist Csikszentmihalyi. ${ }^{1}$ He eloquently depicts the holistic experience of flow in his books [Csikszentmihalyi, 1975; Csikszentmihalyi, 1990]. Flow represents a state of consciousness where a person is so absorbed in an activity that s/he excels in performance without consciously being aware of his or her every movement. Once described, the flow experience is easily recognizable to avid rock climbers, composers, and even Web surfers. Flow theory, developed in the reference discipline of psychology, is used to address optimal user experiences with personal computers [Ghani, 1995; Ghani and Deshpande, 1994; Ghani et al., 1991; Trevino and Webster, 1992; Webster et al., 1993], and the World Wide Web [Chen, 2000; Chen et al., 1999; Hoffman and Novak, 1996; Nel et al., 1999; Novak et al., 2000; Pace, 2004]. Within a computer-mediated environment, the experience of flow is shown to lead to increased:

\footnotetext{
${ }^{1}$ Myhali Csikszentmihalyi is on the faculty of the Drucker-Ito Graduate School of Management at Claremont Graduate University in Claremont California and is Professor Emeritus at the University of Chicago.
} 
- communication [Trevino and Webster, 1992],

- exploratory behavior [Ghani, 1995; Ghani and Deshpande, 1994; Webster et al., 1993],

- learning [Ghani, 1995],

- $\quad$ positive affect [Chen, 2000; Trevino and Webster, 1992], and

- computer use [Ghani and Deshpande, 1994; Trevino and Webster, 1992; Webster et al., 1993].

Therefore, computer-mediated environments (CME) that are conducive to flow would yield positive attitudes and outcomes for users, and have broad implications for e-commerce [Hoffman and Novak, 1996] and learning [Guru and Nah, 2001].

The practical implications of the consequences of flow experiences are clear, important, and promising. It is expected that our understanding of the flow phenomenon would guide information and communication technology (ICT) designers to be able to design a product that will lead users to flow experiences.

From a research perspective, however, flow is ill defined in CME because of the numerous ways it is conceptualized, operationalized, and measured [Koufaris, 2002]. Many questions remain such as the different dimensions flow may have, what makes flow happen, why particular environments or interfaces are more conducive to yielding flow among users, and what methods can be used to measure flow. The lack of rigorous study of the flow phenomenon within CME limits any potential recommendations for ICT designers, trainers, and related stakeholders.

This paper is not intended to provide complete answers to the above questions. We believe that additional research is much needed to answer these questions. Our goal is to point out some of the challenges that researchers face when they study flow within CME. Through a literature review, we identify both conceptual and methodological (operationalization of the constructs and data collection methods) challenges in flow studies. Conceptually, we need to clarify the constructs and the interactions that are most influential to optimal experiences in CME. Methodologically, we demonstrate how the flow experience has been difficult to isolate and study because of its dynamic and holistic nature.

We hope that by identifying concerns and issues from existing studies and noting the challenges, this paper can provide some directions for future research and encourage researchers to work toward viable solutions. We believe that this step is important before substantial progress can be made in studying flow within CME if we are to use the great promise of flow research on ICT design, training, acceptance, and adoption and its impact in enriching people's lives.

\section{THE FLOW MODELS}

The founder of flow theory, Csikszentmihalyi [1975; 1988; 1990], studies optimal experiences of people and outlines factors that are coincident with their experiences. The term 'flow' is adopted by Csikszentmihalyi because this word is repeatedly used by dancers and rock climbers to describe the sensation they experience when in the midst of an optimal experience. Csikszentmihalyi finds that for an activity to lead to this flow state, it must be done for the satisfaction of the activity itself. A person must be motivated intrinsically to do the activity, or autotelic, literally meaning self-goal [Csikszentmihalyi, 1990]. In addition to being autotelic, the activity must be challenging and require skills, merge action and awareness, provide feedback, and require full concentration on the task at hand. Also, the person experiencing flow must have clear goals, feel in control, lose their self-consciousness, and experience a distortion of time [Csikszentmihalyi, 1990]. These factors may not be the only ones that contribute to flow, but Csikszentmihalyi identifies them as the most commonly exhibited ones.

Csikszentmihalyi [1975] describes flow as "the holistic sensation that people feel when they act with total involvement." Precisely defining this holistic sensation and its contributing factors has been difficult for researchers, as evident from the various constructs included in major models 
and the discrepancy of their placement within the models. Csikszentmihalyi writes about flow holistically and from the individual's perspective; his work on flow is more descriptive than predictive.

Building robust predictive models to account for the primary factors influencing flow has been difficult and non-conclusive in CME. Many studies use the flow concept in studying other related constructs such as playfulness, enjoyment, fun, engagement, and cognitive absorption, to name a few [Agarwal and Karahanna, 2000; Atkinson and Kydd, 1997; Webster and Ho, 1997]. Other researchers adapt parts of Flow Theory into other theories or models. For example, a few researchers integrate Flow Theory into the Technology Acceptance Model to incorporate more affective aspects into technology or Website acceptance [Chung and Tan, 2004; Hsu and Lu, 2004; Koufaris, 2002]. Relatively few studies focus on flow exclusively to build models about the flow experience.

In this section, we present brief descriptions of several existing flow models for CME where the flow phenomenon is the main focus of the models. In-depth analysis of these models and other issues follow in Sections III and IV. Additional studies that focus on flow but do not provide a flow model [Huang, 2003; Pace, 2004; Pilke, 2004; Trevino and Webster, 1992] will also be reviewed as appropriate.

\section{GHANI}

Ghani develops a model of flow in human-computer interaction [Ghani, 1995]. His model, shown in Figure 1, places fitness of task (i.e., the difference between challenges and skills), perceived control, and cognitive spontaneity ("playfulness") as the antecedents of flow. Flow itself is measured through the constructs of enjoyment and concentration. The consequences of flow are a focus on the process, increased learning, and increased creativity. Ghani's work illustrates the complexity of the balance of a user's skills and challenges. With an excess of skills, the user feels more in control, which can lead to flow. However, when the skills greatly exceed challenges, boredom will likely result, providing a negative influence on flow. After testing the model, Ghani finds that the construct of fit (challenges and skills) influences flow indirectly, mediated through perceived control.

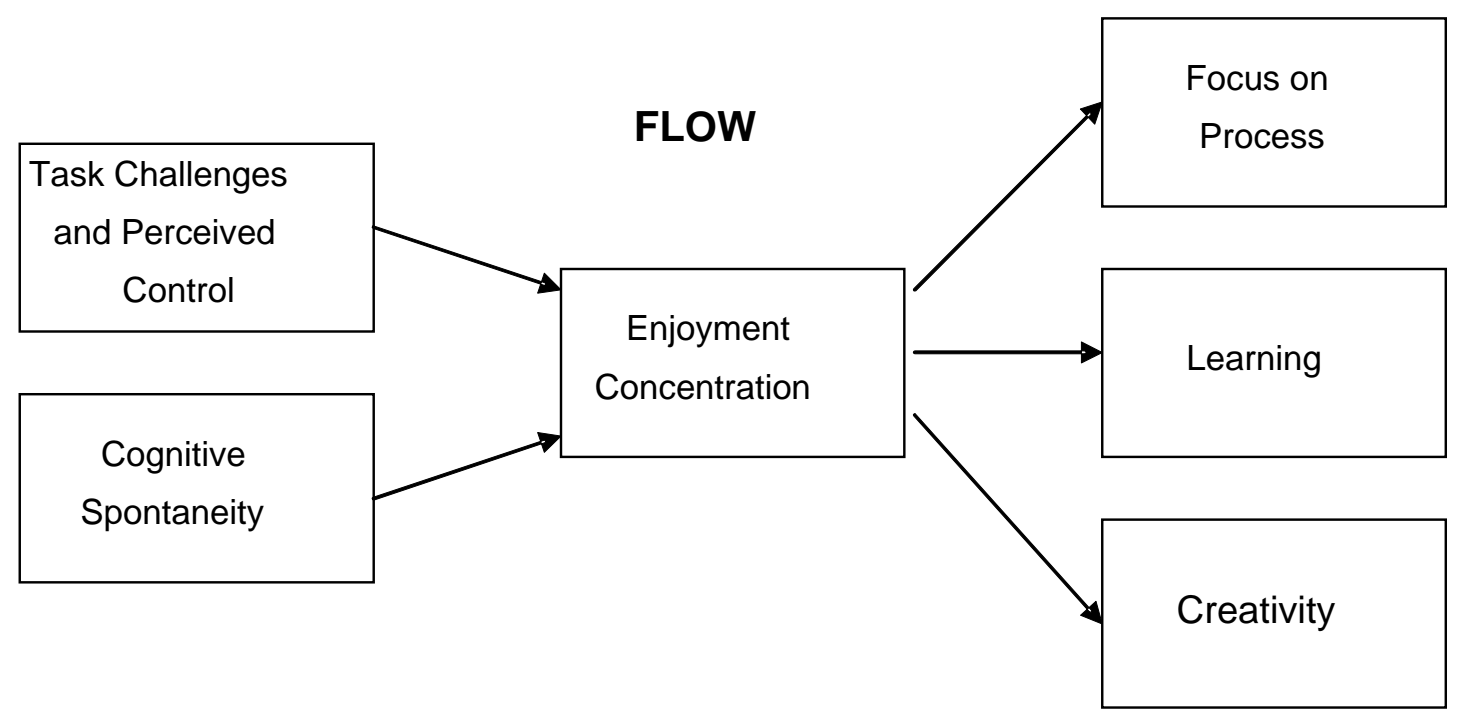

Adapted from Ghani [1995]

Figure 1. Model of Flow in Human Computer Interaction 


\section{HOFFMAN AND NOVAK}

Hoffman and Novak [1996] develop a theoretical model of flow within the hypermedia environment of the Web (Figure 2). Though later Novak, Hoffman and Yung [2000] make some substantial changes in the "1996" conceptual model they refer to in their 2000 work, we believe that their 1996 model, as originally conceived, is important to consider. Following Csikszentmihalyi's work, Hoffman and Novak [1996] indicate that the primary antecedents to flow are challenges, skills, and focused attention. From the literature on communication media, they add secondary antecedents: interactivity and telepresence. Steuer [1991] defines telepresence as "the extent to which one feels present in the mediated environment, rather than in the immediate physical environment." Steuer further identifies vividness and interactivity as the two dimensions that determine the degree of telepresence within a particular technology. Hoffman and Novak incorporate Seuer's two dimensions into their model as content characteristics that directly influence telepresence and focused attention. Hoffman and Novak add the construct of involvement, which encompasses intrinsic motivation and self-reliance and is influenced by whether the activity is goal-directed or experiential. They label goal directed and experiential as process characteristics.

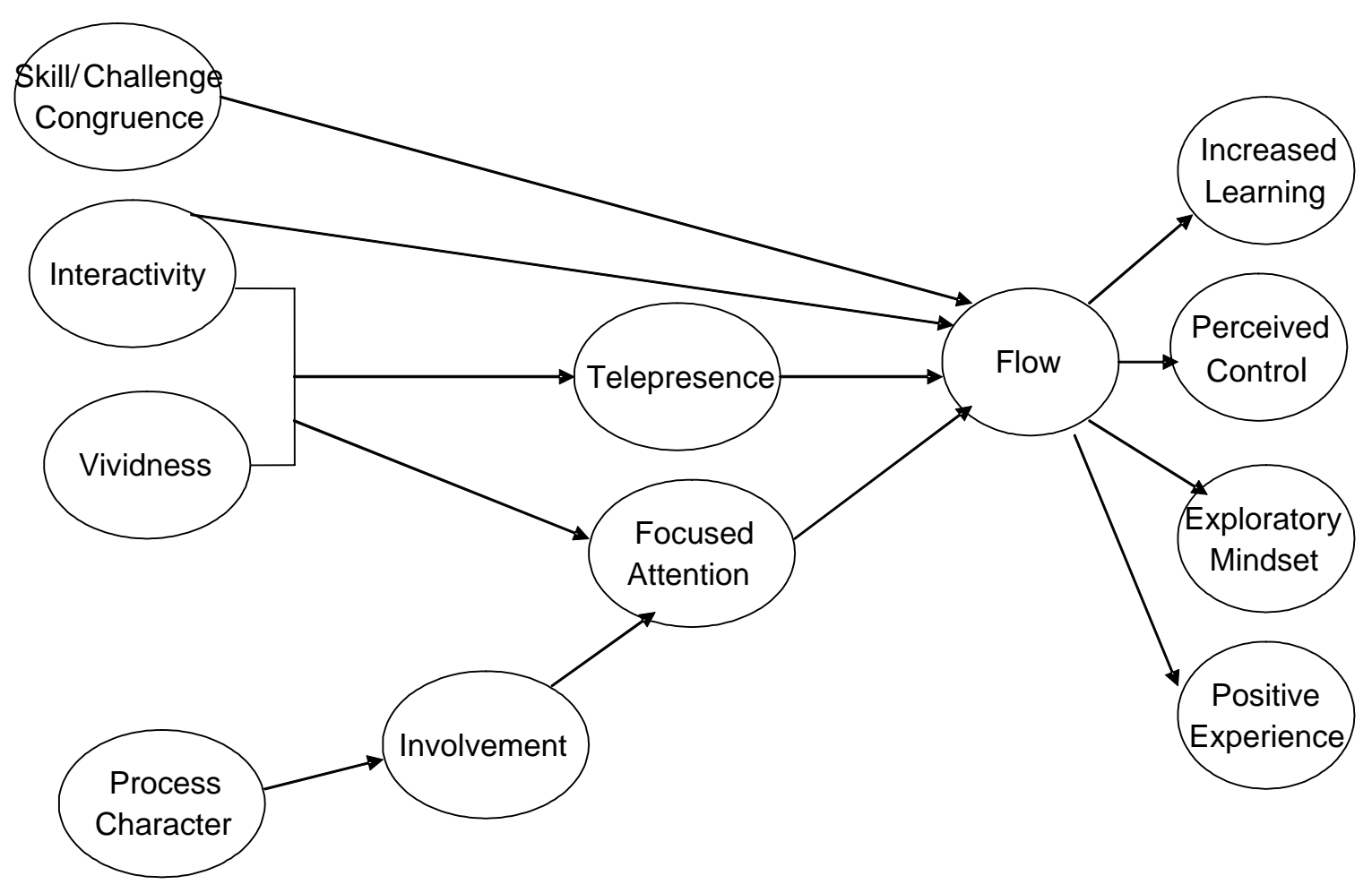

Adapted from Hoffman and Novak [1996]

Figure 2. Conceptual Model of Flow within a Computer-Mediated Environment

Hoffman and Novak's 1996 model shows the consequences of flow as increased learning, perceived control, exploratory mind-set, and positive subjective experience. In 2000, Novak et al. [2000] make some adjustments to their 1996 theoretical model and test it empirically using structured equation modeling to create a revised theoretical model. One important change is that the control construct is moved from a consequence to an antecedent of flow. The construct arousal is added as an antecedent of flow, and is a dependent variable of challenge. 
The revised model (Figure 3) shows that the importance construct directly influences not only focused attention, but also the level of challenge and skill. Interactive speed influences challenge. Focused attention still influences telepresence but interactivity does not. Telepresence is shown to influence exploratory behavior directly, as well as through the flow construct. To summarize, in the revised model, the primary antecedents of flow are skill/control, challenge/arousal, and focused attention. The secondary antecedents are experience with the Web, interactive speed, and importance. Surprisingly, Novak et al. do not find support for the hypothesis that greater flow corresponds to greater exploratory behavior. Instead, exploratory behavior corresponds with telepresence. Thus, telepresence contributes to flow and exploratory behavior.

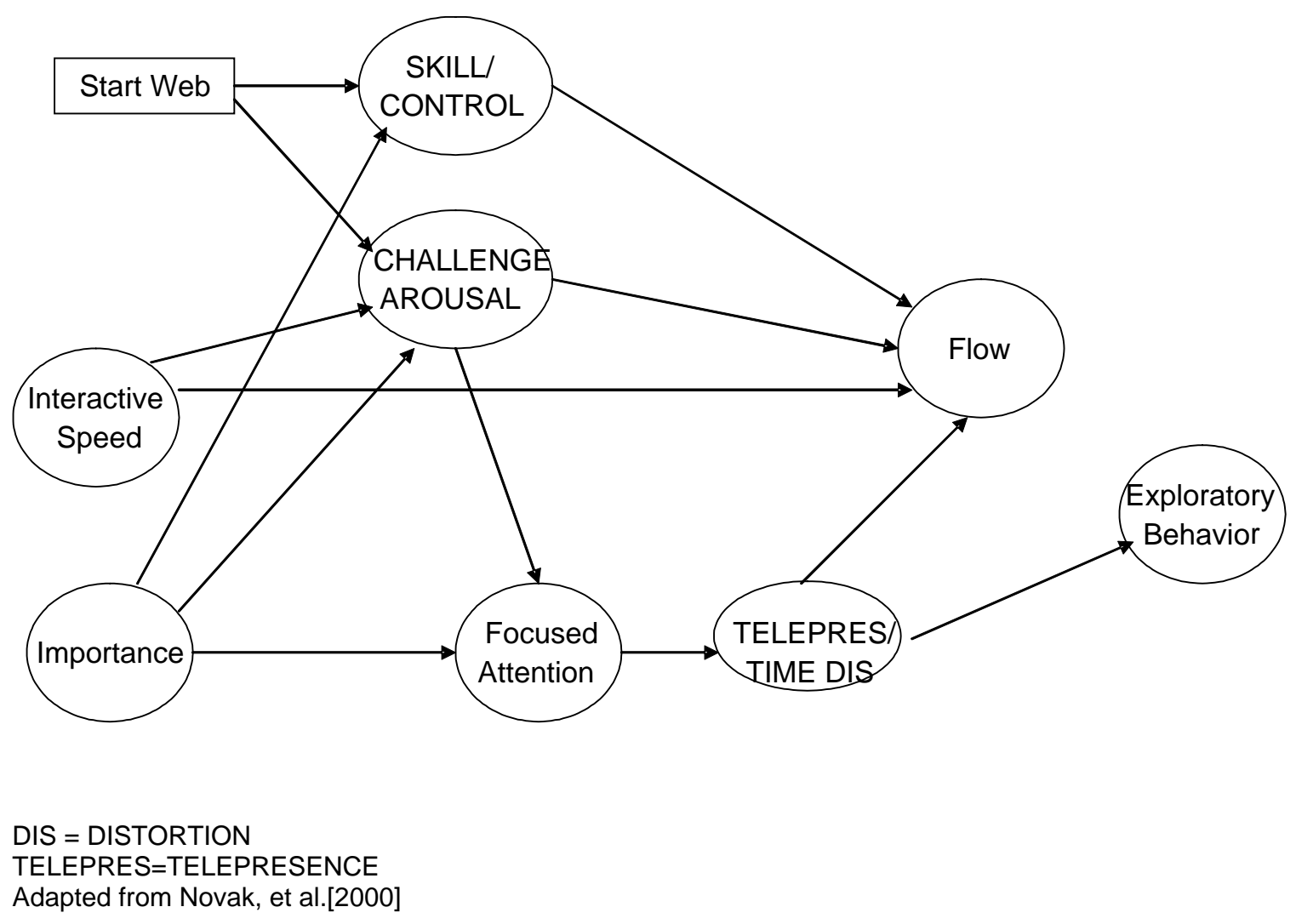

Figure 3. Revised Theoretical Model of Flow

Novak et al. [2003] later empirically test the impact of process characteristics and find that goaldirected processes are more conducive to flow than experiential ones.

\section{CHEN}

In Chen's dissertation [2000], he finds empirical evidence for a correlation between a Web user's flow experience and the ten flow dimensions originally noted by Csikszentmihalyi [1990]. Using factor analysis, Chen breaks down the ten dimensions into three factors labeled flow antecedents, flow experience, and flow consequences (Figure 4). The flow antecedents are clear goals, immediate feedback, potential control, and merger of action and awareness. The flow experience dimensions are concentration, telepresence, time distortion, and loss of selfconsciousness. The flow consequences are positive affect and autotelic experience. The merger of action and awareness is the only dimension that does not clearly fall into one factor. Because its highest loading is in the flow antecedents factor, Chen places it there. 


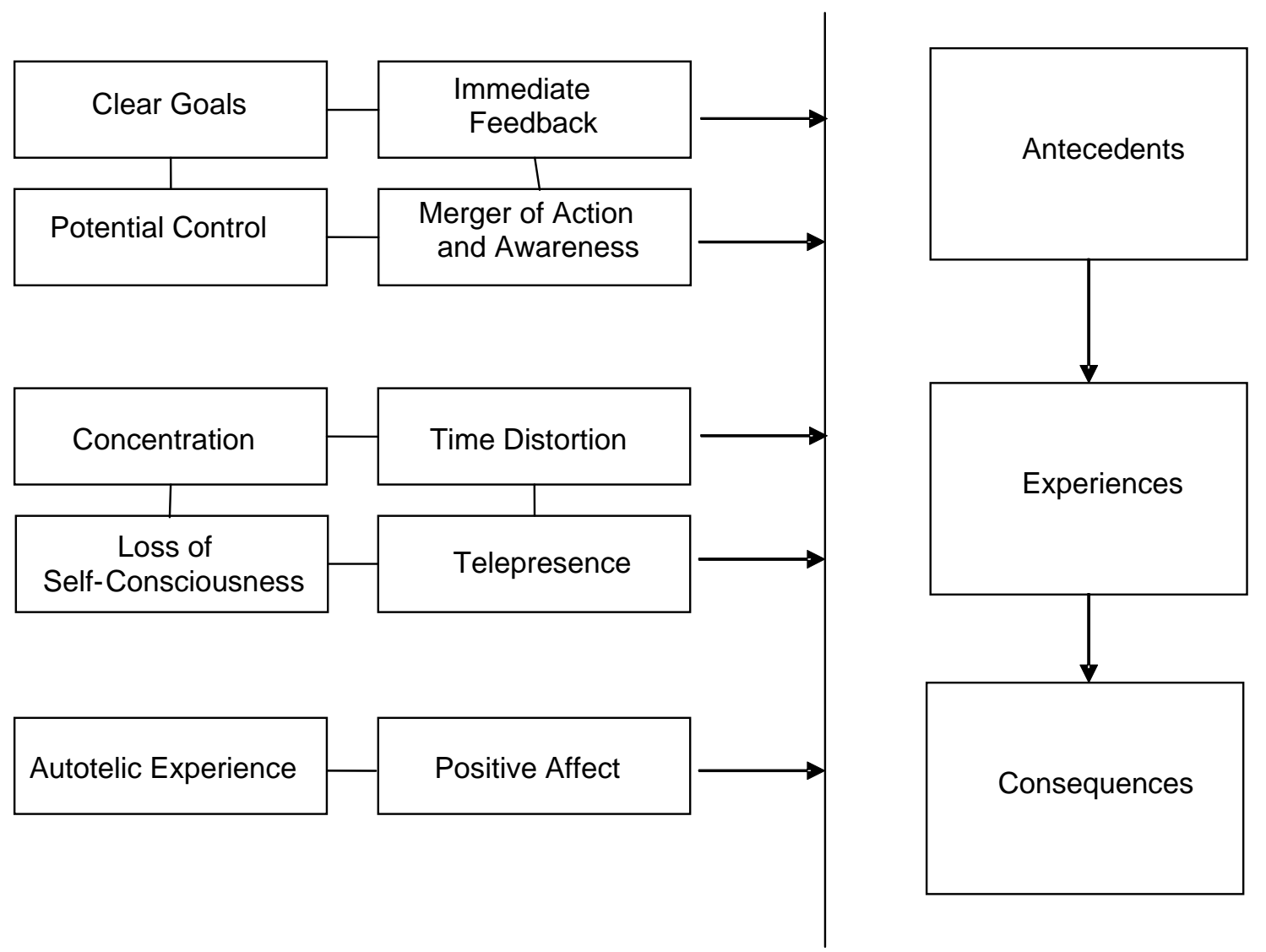

Adapted from Chen[2000]

Figure 4. Model of Flow

\section{SKADBERG AND KIMMEL}

Skadberg and Kimmel [2004] propose a flow model to predict the level of flow for a tourism website (Figure 5). The user's domain knowledge represents her skill and the content of the Web pages represents the challenge. The third direct antecedent of flow is telepresence, which is influenced by site attractiveness and interactivity, the latter is further influenced by speed and ease of use. Flow is measured by time distortion and enjoyment. The consequence of flow is increased learning, which impacts attitude and behavior.

\section{COMPARISON OF MODELS}

Table 1 demonstrates that each of these models is unique. Some of the constructs are present in all of the models, while others are unique to a particular model. The same concepts may be referred to with different construct names. 


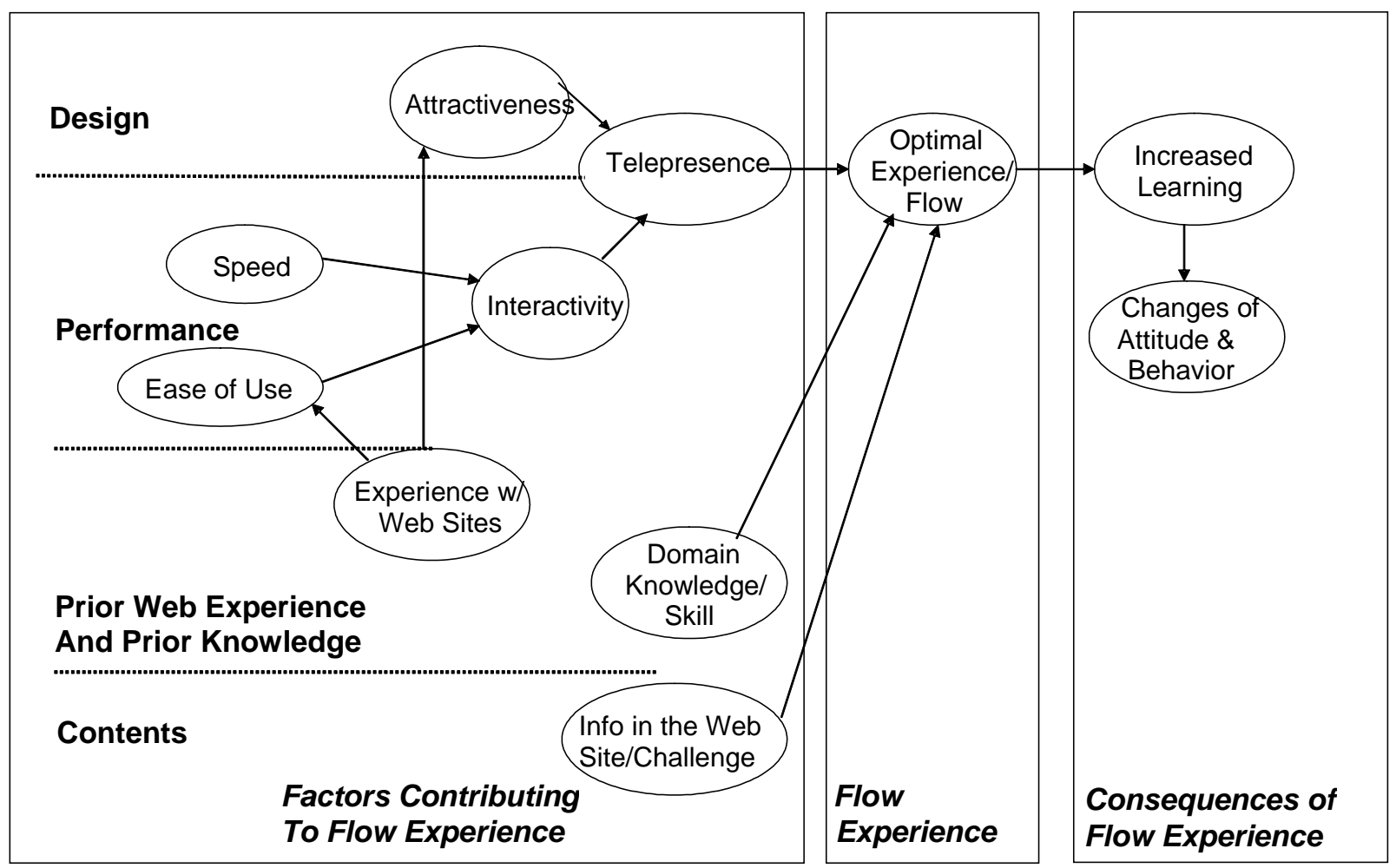

Adapted from Skadberg and Kimmel [2004]

Figure 5. Flow Model within Context of Tourism Website

While Ghani [1995] and Chen [2000] focus on primary antecedents, Hoffman and Novak [1996] and Skadberg and Kimmel [2004] also look at secondary or indirect antecedents that yield flow through a mediating construct. We discuss these discrepancies in detail in Section III.

In general, the models and other empirical flow studies in CME seem to suggest the following three stages as a flow framework, as depicted on the right side of Figure 4:

- flow antecedents,

- flow experience, and

- flow consequences [Chen, 2000; Ghani, 1995; Ghani and Deshpande, 1994; Trevino and Webster, 1992].

Novak et al.'s empirical work in 2000 shows more complex interactions, with some constructs having direct and indirect influences on flow. However, their earlier theoretical model in 1996 uses this common framework of flow antecedents, experience, and consequences. They deviate only slightly by distinguishing between primary and secondary antecedents. Chen [2000] validates the three stages with factors included in his study. Though some debate exists as to which factors belong in each stage of flow, the structure of Flow Antecedents, Flow Experience, and Flow Consequences is generally agreed upon. 
Table 1. Constructs within Flow Models

\begin{tabular}{|c|c|c|c|}
\hline Study & Flow Antecedents & Flow Experience & Flow Consequences \\
\hline Ghani [1995] & $\begin{array}{l}\text { Fit: balance of challenges and } \\
\text { skills in the activity } \\
\text { Perceived Control } \\
\text { Cognitive Spontaneity }\end{array}$ & $\begin{array}{l}\text { Enjoyment } \\
\text { Concentration }\end{array}$ & $\begin{array}{l}\text { Focus on Process } \\
\text { Learning } \\
\text { Creativity }\end{array}$ \\
\hline $\begin{array}{l}\text { Hoffman and } \\
\text { Novak [1996] }\end{array}$ & $\begin{array}{l}\text { Skill/Challenge Congruence } \\
\text { Telepresence } \\
\text { Interactivity } \\
\text { Vividness } \\
\text { Focused Attention } \\
\text { Interactivity } \\
\text { Vividness } \\
\text { Involvement } \\
\text { Process Character } \\
\end{array}$ & & $\begin{array}{l}\text { Increased Learning } \\
\text { Perceived Control } \\
\text { Exploratory Mindset } \\
\text { Positive Experience }\end{array}$ \\
\hline Chen [2000] & $\begin{array}{l}\text { Clear Goals } \\
\text { Immediate Feedback } \\
\text { Potential Control } \\
\text { Merger of Action and Awareness }\end{array}$ & $\begin{array}{l}\text { Concentration } \\
\text { Time Distortion } \\
\text { Loss of Self-consciousness } \\
\text { Telepresence }\end{array}$ & $\begin{array}{l}\text { Autotelic Experience } \\
\text { Positive Affect }\end{array}$ \\
\hline $\begin{array}{l}\text { Skadberg and } \\
\text { Kimmel [2004] }\end{array}$ & $\begin{array}{l}\text { Skill: visitors knowledge of the } \\
\text { Web site topic } \\
\text { Challenge: Web page content } \\
\text { Telepresence } \\
\text { Attractiveness } \\
\text { Experience w/Web sites } \\
\text { Interactivity } \\
\text { Speed } \\
\text { Ease of Use }\end{array}$ & $\begin{array}{l}\text { Enjoyment } \\
\text { Time distortion }\end{array}$ & $\begin{array}{l}\text { Increased Learning } \\
\text { Changes of Attitude and } \\
\text { Behavior (indirect, } \\
\text { through learning) }\end{array}$ \\
\hline
\end{tabular}

\section{CONCEPTUAL CHALLENGES OF FLOW IN CME}

This section highlights the three conceptual challenges demonstrated by the models introduced previously.

1. The discrepancies of the constructs and their structure within each model.

2. A frequent omission in the empirical models: individual differences.

3. An important distinction between the artifact and the task, which should help to define the flow antecedent constructs more precisely.

\section{CONSTRUCT DISCREPANCIES WITHIN THE FLOW MODELS}

The reliability of flow constructs among studies is low. In a review of the constructs used in major flow studies, including traditional and computer-mediated flow work from 1977 to 1996, Novak et al. [2000] list the thirteen constructs shown in Table 2.

Table 2. Flow Constructs (from Novak et al. [2000])

\begin{tabular}{|l|l|l|l|}
\hline challenges & skills & focused attention & control \\
\hline positive affect & involvement & interactivity & playfulness \\
\hline time distortion & arousal & exploratory behavior & optimum stimulation level \\
\hline telepresence & & & \\
\hline
\end{tabular}

Of the sixteen studies reviewed, Novak et al. find that on average each study only considers four of the thirteen constructs. Novak et al. attempt to incorporate these thirteen constructs in their model. However, it is not agreed upon in the literature that these thirteen are exhaustive of the flow constructs. In Chen's [2000] dissertation, three out of the ten dimensions he studies arguably are not within Novak et al.'s list. The three missing dimensions (clear goals, merger of 
action and awareness, and loss of self-consciousness) are hardly unimportant; they are directly from Csikszentmihalyi's work.

As the flow models in Section II illustrate, the discrepancies are considerable. Ghani [1995] and Chen [2000] consider perceived control to be an important antecedent yet it is a consequence in Hoffman and Novaks's [1996] model and altogether missing from Novak et al.'s [2000] empirical model. Hoffman and Novak [1996] and Novak et al. [2000] include aspects of the interface such as interactivity in their model, yet Chen ignores such characteristics. Some of the omissions or inclusions are justifiable because researchers may be studying different influences on the flow experience. Nonetheless, it would be expected that with the amount of effort that went into studying the flow phenomenon, we would have a cadre of standard constructs to include in a flow study. Judging from these models, challenges and skills are the only indispensable constructs for studying flow. This situation is ironic given that flow is as much of an affective state as a performance state.

In addition to discrepancies about which constructs are important for the flow model, some models place the constructs in different stages of the flow model. Ghani $[1991,1995]$ considers concentration and enjoyment as the flow experience itself, while others [e.g., Chen, 2000; Novak et al., 2000] place concentration as an antecedent to flow and enjoyment as a consequence of flow. Structured equation modeling enables researchers to break down the aspects of flow and show the direct and indirect influences of the many dimensions on flow; however, this can lead to some problematic results. In Novak et al.'s [2000] work, telepresence, originally conceived as being an antecedent, is shown to influence not only flow but also exploratory behavior, a construct that was expected to result from the flow experience. Thus, their work does not show the flow experience itself yielding any consequences.

Inconsistent flow models pervade the literature. To some extent, developing and testing new versions of the flow model seem very necessary as they can expand our thinking and ideally resolve the inconsistencies. On the other hand, the discrepancies of these models may indicate a deeper problem on the underlying conceptualization of flow theory in CME [Finneran and Zhang, 2003]. Without realizing and resolving this conceptualization problem first, any more flow models will only add to and worsen the already inconsistent understanding. We will revisit this conceptualization problem with regard to antecedents in the subsection on ambiguity below.

\section{INDIVIDUAL FACTORS}

Notable studies on users of information systems find evidence that time and space specific factors can predict user behavior better than individual differences [Dervin et al., 1982; Newby et al., 1991]. However, flow is less about predicting behavior and more about predicting a person's affective state (which may in turn influence behavior). Individual differences can yield very different flow experiences from the same activity. A flow study by Ellis et al. [1994] directly compares models that incorporate individual personality difference with models that do not. This study finds that individual difference account for as much as $20 \%$ of the variance. Clearly, accounting for individual differences is important for a robust flow model.

Most CME flow studies incorporate individual differences of the user's experience level or skill in using computers or the World Wide Web (WWW). Researchers use objective measures (e.g., years using the WWW [Hoffman and Novak, 2000]), and/or self-reports, (users indicate their skill level on a Likert-type scale [Ghani, 1995, Hoffman and Novak, 2000]). The differences among individuals, however, is not merely in their skills, but also in their underlying life attitude, or their 'autotelic personality' [Csikszentmihalyi, 1988]. In a study of high-schoolers faced with their first ever term paper exercise, the quality of the term paper is found to correlate more with the student's overall emotional state toward the exercise than the student's prior grades and writing experience [Larson, 1988].

Though 'autotelic personality' is identified as an essential part of the flow model by Csikszentmihalyi, few researchers include it in their models. Hoffman and Novak [1996] address 
an individual's optimum stimulation level (OSL) in their conceptual model. However, their empirical work aimed at testing the conceptual model does not include OSL [Novak et al., 2000]. 'Autotelic personality' is probably more connected to intrinsic enjoyment [Csikszentmihalyi, 1990; Hamilton et al., 1984] than to stimulation, as Csikszentmihalyi [1990] shows that some persons can experience flow while partaking in the most mundane of activities.

Ghani's [1995] experiment uses the construct of cognitive spontaneity to measure individual playfulness. He refines the Adult Cognitive Spontaneity scale used by Webster [1989] and originally developed by Lieberman [1977]. Novak et al. [Novak et al., 2000] also collect data on playfulness in their survey, but it is not clear how they use it in their model. Cognitive playfulness, or "playing with ideas" [Lieberman, 1977], in itself is shown to increase performance and positive affect in the context of learning computer applications [Martocchio and Webster, 1992]. It is unclear if flow must mediate this relationship or if it merely heightens the performance and affect.

Playfulness is a stable trait [Yager et al., 1997] while some traits such as cognitive absorption can be considered both a trait and a state [Agarwal and Karahanna, 2000]. Finneran and Zhang [2003] argue that conceptually a model of flow must consider an individual's state as well as his or her traits. A person's state is dynamic and will influence the possibility of entering a flow state at a particular moment in time.

More studies are needed within the area of individual differences and 'autotelic personality' to help researchers clarify which individual measures influence the flow experience and where they occur in the process.

\section{AMBIGUITY AMONG ACTIVITIES, TASKS AND ARTIFACTS}

Existing studies on flow in CME do not clearly distinguish between an activity and a task or between a task and an artifact. We will discuss these concerns respectively, and briefly summarize a solution proposed by Finneran and Zhang [2003].

\section{Activities and Tasks}

Prior studies consider "using the web" as an activity [e.g., Novak et al., 2000], while others focus more generally on "using computers" [e.g., Ghani and Deshpande, 1994] or more specifically, "evaluat[ing]...web sites" [Nel et al., 1999]. Yet, the user's goals of using the Web or computers are unclear.

The flow experience is associated with a person doing an activity. In traditional flow studies, the activities tend to be very clear: playing music, climbing a cliff, playing chess, or reading a book. These activities involve clear goals that the persons studied are aware of and the researchers can easily identify. In these studies, the tools that are required to accomplish the activities are not considered as a meaningful hindrance to the activity, and therefore, given little attention. For example, a rock climber may need to use a variety of tools to accomplish a climb and a musician needs to play an instrument to make music. These tools are not taken into much consideration in studying flow because it is assumed that they are well mastered by the people who experience flow [Finneran and Zhang, 2003]. Thus, in the original flow studies one could simply treat activity and task interchangeably.

In CME, however, the activity is nebulous. "Using the Web" does not by itself demonstrate a clear goal. The Web could be used for finding vacation packages, playing an online bridge game, or finding information concerning a medical condition. The actual activity would be the combination of using the Web (as a means) and the specific tasks related to the activity. One can experience flow by using another medium to accomplish the same task, such as using a print catalog for finding vacation packages. Thus the Web functions more like a tool than an activity in these examples. Table 3 lists the tasks that users are required to do for the empirical studies reported. Fortunately, in the more recent studies, the tasks are more specific and focused on an activity rather than the tool itself. 
Table 3. Tasks the Subjects Are Involved with for Empirical Flow Studies

\begin{tabular}{|l|l|}
\hline Empirical Study & Task \\
\hline Trevino and Webster [1992] & No task specified: general work communication \\
\hline Ghani [1995] & Class assignment which required specific graphics software \\
\hline Novak et al [2000] & No task specified: general Web use \\
\hline Chen [2000] & Use the Web for user-selected task \\
\hline Huang [2003] & No task specified: regularly visited Websites \\
\hline Pearce et al [2004] & Learn about physics through online learning exercise \\
\hline Skadberg and Kimmel [2004] & Visit a tourism Website for a particular place (Texas Coastal Bird Trail) \\
\hline
\end{tabular}

\section{Artifacts}

Finneran and Zhang [2003] choose the broad term, artifact, because it is a more neutral term than tool or toy. Tools denote "systems used for external sake [Malone, 1981]," while toys denote "systems used for own sake [Malone, 1981]." According to Csikszentmihalyi's theory [1990], a flow experience would be more typical when a user is interacting with a toy. However, studies show that users experience flow while using tools like word processors and email packages [Ghani and Deshpande, 1994; Trevino and Webster, 1992].

The mastering of artifacts within CME cannot be taken for granted due to their dynamic nature and the complex interactions humans must have with them. Finneran and Zhang suggest that activity needs to be divided into two components: the task or main goal of the activity and the artifact that assists the user in accomplishing the task [Finneran and Zhang, 2003].

Within CME, an artifact may influence flow substantially, for example by increasing a user's likelihood to experience telepresence or to stay focused on the underlying task. To expand on the important construct of telepresence, it can be broken down into the contributing factors of

- $\quad$ vividness, (comprised of breadth, depth and speed), and

- interactivity (comprised of range, and mapping) [Steuer, 1991].

Using these variables, a researcher could compare different artifacts and study how they might lead to a higher degree of telepresence and thus flow. This telepresence example shows how artifacts and their impact on flow could be studied. Telepresence is just one possibility in comparing different media. Hoffman and Novak [1996] develop a typology of communication media on two poles:

- static/dynamic and

- impersonal/personal.

Further, Guru and Nah [2001] apply the media richness theory [Daft and Lengel, 1986] to study flow within a learning environment.

\section{Proposed Model for Differentiating Tasks and Artifacts}

Most existing flow studies in CME do not differentiate clearly between factors that are related to the task and those related to the artifact. For example, the construct of immediate feedback is confusing in the context of an online activity. When composing e-mail, would the feedback be from the e-mail software package or from the receiver of the e-mail? We can label the former as machine interactivity and the latter as person interactivity [Hoffman and Novak 1996]. Steuer [1991] defines machine interactivity as, "the extent to which users can participate in modifying the form and content of a mediated environment in real time." The distinction between personinteractivity and machine-interactivity clarifies the feedback construct within the online environment. By differentiating between the artifact (i.e., email software) and the task (i.e., 
correspondence with a person), we can consider the flow dimensions that occur with both of these aspects.

Thus, there is a need to re-conceptualize flow in CME to consider the uniqueness of the artifacts (i.e., ICTs) and the complexity they add to the flow phenomenon. As an attempt to reconceptualization, Finneran and Zhang [2003] propose a conceptual model for flow antecedents: the Person-Artifact-Task (PAT) model. PAT removes the ambiguities among the flow antecedents by considering the task and the artifact as separate entities when looking at the factors that lead to a flow state. Finneran and Zhang [2003] consider each of the three main components of person, artifact, and task independently and their interactions, to understand the holistic picture of flow antecedents. The model is a high-level one intended to help researchers clearly conceptualize and design their flow studies.

The PAT model emphasizes only the flow antecedents stage, not the entire flow framework. Nevertheless, it is a start of the re-conceptualization process. Better conceptualization of flow experiences and flow consequences are also needed. As the literature shows, understanding of these two stages is not agreed upon.

The re-conceptualization hopefully can contribute to clarifying some of the conceptual discrepancies found in the existing flow models and lead to productive studies to develop rigorous flow models with well-defined flow constructs.

\section{METHODOLOGICAL CHALLENGES OF STUDYING FLOW IN CME}

Studying flow with traditional activities is challenging methodologically, yet these challenges are even greater when studying flow in CME. Since the 1990's, researchers have studied the flow phenomenon in computer-mediated communication [Ghani et al., 1991; Trevino and Webster, 1992], office productivity software on desktop computers [Ghani, 1995; Ghani and Deshpande, 1994; Webster et al., 1993], and general Web activity [Chen, 2000; Chen et al., 1999; Pace, 2004]. In this section, we investigate the challenges that these and other studies faced in the operationalization and data collection phases of the research project.

\section{OPERATIONALIZATION}

The balance of skills to challenges is theoretically the most important factor to a flow experience [Csikszentmihalyi, 1990; Massimini and Carli, 1988] yet, operationalizing the skill/challenge ratio is troublesome. Ellis et al. [1994] believe that the skill and challenge constructs are complex, and that unidimensional scales may not serve as valid measures. They note that these constructs could be measuring emotional, mental, or physical challenges and skills. A research question is: must the emotional, mental, and physical aspects be focused on the same activity to achieve an optimal experience? It would seem that Csikszentmihalyi's criterion of merging action and awareness would dictate so. To date, empirical research primarily measure unidimensional skills and challenges. For example, Novak et al.'s [2000] measure of skills and challenges focuses on the medium or artifact (i.e., using the Web), ignoring the underlying task (e.g., finding a low airfare). A recent empirical study that inductively studies flow through interviews finds that the most frequently cited obstacle to attaining a flow state is insufficient user interface skills [Pilke, 2004]. Contrarily, another recent study operationalizes skills and challenges according to the domain knowledge and content of a website rather than the medium or artifact [Skadberg and Kimmel, 2004].

In addition to the ambiguity of what types of challenges and skills should be measured, many respondents do not fare well when asked directly to measure such constructs. Chen et al.'s [1999] respondents of the first sample were asked, Have you ever experienced the feeling of "positive challenge" during your Web navigation? Many of them (14\%) wrote comments stating they did not understand the question. The researchers then added the option I don't understand what positive challenge means and $38 \%$ of the second sample respondents selected this option. Likewise, many users were unfamiliar with the idea of control, another important factor in the flow 
model. When asked the question, Have you ever experienced the feeling of "being in control" during your Web navigation? Of the $1^{\text {st }}$ sample $25 \%$ commented they did not know what it meant, and when an I don't know option was added, $18 \%$ of the $2^{\text {nd }}$ sample selected it. Novak et al. [2000] also note a problem with the measurement of control in their study because the reliability for the control construct is below 0.6. Similarly, as one of the five dimensions of cognitive absorption in Agarwal and Karahanna's study [2000], control's loading is 0.64, lower than each of the other dimensions and the guideline of .70.

Because of the conceptual vagueness of flow, operationalizing the flow construct itself has been inconsistent in the empirical work (Table 4). Some studies estimate flow by measuring the subject's sense of control, focused attention, curiosity, and intrinsic interest [Nel et al., 1999; Trevino and Webster, 1992; Webster et al., 1993]. Other studies estimate flow by measuring enjoyment and concentration [Ghani, 1995; Ghani and Deshpande, 1994; Ghani et al., 1991]. To maintain the holism of the flow construct, some researchers [Chen, 2000; Chen et al., 1999, Novak et al., 2000] operationalize flow by asking the subjects to read three actual quotations describing the flow experience and rate how accurately each of the quotations represents their experience. For example, one quotation reads: My mind isn't wandering. I am not thinking of something else. I am totally involved in what I am doing. My body feels good. I don't seem to hear anything. The world seems to be cut off from me. I am less aware of myself and my problems [Chen et al, 1999].

In summary, operationalizing the challenge/skill ratio, a key determinant of an optimal experience, needs serious and creative thought. This construct must be measured reliably before flow studies can progress. We see more success with the research to date in operationalizing the flow state itself. Researchers are reporting satisfactory results from the subject assessing their whole state to a flow state by rating how similar they feel to that of a quotation from a person who is experiencing flow.

\section{DATA COLLECTION METHODS}

Because of its dynamic and affective nature, data on flow experiences are difficult to collect. We will discuss the advantages and disadvantages of the various methods that have been used to study flow: the Experience Sampling Method (ESM), Experiments, Surveys, and Qualitative Techniques.

\section{Experience Sampling Method}

Most of the traditional flow studies are naturalistic. The popular Experience Sampling Method (ESM), a signal-contingent approach [Csikszentmihalyi and Larson, 1992; Larson and Delespaul, 1992], is developed by Csikszentmihalyi et al., [1977] to examine flow experiences in everyday life. Typically in these studies, for one or two weeks, the subjects would wear a device that signals periodically, at which time the subjects would record their activity and self-report their state [Clarke and Haworth, 1994; Csikszentmihalyi and Csikszentmihalyi, 1988; Haworth and Evans, 1995]. The ESM enables researchers to examine the dynamic nature of flow within an individual. It is an appropriate method when studying flow experience in daily life and comparing flow across various life activities. However, the ESM is not conducive to studying one particular activity, especially if the activity does not occur at predictable times throughout the day. This method can be inefficient because the device will inevitably signal when the subject is not engaged in the specific activity being investigated. 
Table 4. Operationalization of Flow in Major Empirical Flow Studies

\begin{tabular}{|c|c|}
\hline Study & Operationalizing Flow \\
\hline Ghani [1995] & $\begin{array}{l}\text { The constructs with the following indicators (1-7 Likert scale) } \\
\text { Enjoyment } \\
\text { Interesting } \\
\text { Fun } \\
\text { Exciting } \\
\text { Enjoyable } \\
\text { Concentration (refined in follow-up study) } \\
\text { Was deeply engrossed in activity } \\
\text { Was absorbed intensely in activity } \\
\text { Attention was focused on the activity } \\
\text { Concentrated fully on activity }\end{array}$ \\
\hline Novak et al [2000] & Narrative description of flow \\
\hline Chen [2000] & Flow quotations from Csikszentmihalyi \\
\hline Huang [2003] & $\begin{array}{l}\text { Control } \\
\text { When navigating this website, I felt in control. } \\
\text { I felt that I had no control over my interaction with the Web. } \\
\text { This website allowed me to control the computer interaction. } \\
\text { Attention focus } \\
\text { When navigating this website, I thought about other things. } \\
\text { When navigating this website, I was aware of distractions. } \\
\text { When navigating this website, I was totally absorbed in what I was doing. } \\
\text { Curiosity } \\
\text { Navigating this website excited my curiosity. } \\
\text { Interacting with this website made me curious. } \\
\text { Navigating this website aroused my imagination. } \\
\text { Intrinsic Interest } \\
\text { Navigating this website bored me. } \\
\text { Navigating this website was intrinsically interesting. } \\
\text { This website was fun for me to use. }\end{array}$ \\
\hline Pearce et al [2004] & $\begin{array}{l}\text { Flow-process measure } \\
\text { How challenging did you find this activity? \{too low | just right | too high\} } \\
\text { Were your skills appropriate for understanding this last activity? \{too low | just } \\
\text { right | too high\} } \\
\text { Overall flow-state measure } \\
\text { I felt in control of what I was doing } \\
\text { I was absorbed intensely by the activity } \\
\text { I found the activities enjoyable } \\
\text { I thought about other things } \\
\text { I found the activities interesting } \\
\text { I was frustrated by what I was doing } \\
\text { The activities bored me } \\
\text { I was aware of distractions } \\
\text { The activities excited my curiosity } \\
\text { I knew the right thing to do } \\
\text { It required a lot of effort for me to concentrate on the activities }\end{array}$ \\
\hline $\begin{array}{l}\text { Skadberg and Kimmel } \\
\text { [2004] }\end{array}$ & $\begin{array}{l}\text { Time Distortion (1-5 Likert scale) } \\
\text { While I was browsing the Web pages, time seemed to go by very quickly } \\
\text { Enjoyment (1-5 Likert scale) } \\
\text { Overall, I enjoyed the virtual tour }\end{array}$ \\
\hline
\end{tabular}

Wheeler and Reis [1991] recommend using event-contingent methods rather than signalcontingent methods when studying a "limited number of human activities, when these events can 
be defined clearly for subjects, and when it is important to obtain a large number of events." Similar to the ESM, for one to two weeks subjects self-report after they participate in a particular activity. Event-contingent methods enable a researcher to collect many data points for the same activity but depend on the subjects to report consistently when they participate in the activity.

Chen and Nilan [1998] adapt the ESM to be more event-contingent for studying Web browsing. They install a signaling device on computer laboratory terminals with Web browsers that would pop-up every 5 to 7 minutes with a questionnaire for the subject to complete. This method remains somewhat naturalistic in that subjects are able to use the Web browser however they want for the designated time period.

\section{Experiments}

Other studies [Ghani, 1995; Ghani et al., 1991; Nel et al., 1999; Webster et al., 1993] use experiments to study flow. Experiments provide a controlled environment in which the researcher can compare how different skill levels or Web site types influence the degree of flow experienced. However, experiments raise questions about the external validity of the study, especially given that flow is a context-specific experience. For example, in the Nel et al. [1999] study, naïve Web users evaluate specific Web sites and then complete a questionnaire on their feelings of control, attention, curiosity, and intrinsic interest. Nel et al. find that Web sites that focus on information communication, as opposed to transactions, yield a higher degree of flow. The experiment itself may hinder the applicability of the findings. When persons are merely evaluating a Web site, information communication may be more enticing than transactions. However, when a user actually intends to complete the transaction, the transaction-based site most likely will surpass the general information site as being more exciting. Thus, it is the task and the context that create the flow experience, not merely the Web site type.

When studying flow across media, it is even more difficult to do controlled experiments and retain external validity. Griffith et al. [2001] compare retail catalogs in print and online within a controlled experiment. They normalize the information in both of the catalogs, primarily removing additional information from the online catalog. The findings indicate that subjects experience more involvement with the print catalogs. However, the limitations of the controlled experiment limit the real-world implications of this study. In natural settings, online catalogs may encourage involvement because they enable users to drill down more quickly to deeper levels of information. The different characteristics [Hoffman and Novak, 1996] and potentially different uses of media must be considered when studying involvement or flow experiences.

The closer a study can be designed so that the subject is experiencing life as they usually do, the more valid a flow study will be. Reaching flow is context-based, dependent not only on the activity a person is undertaking, but also his/her state of mind. Unless thoughtfully designed, experiments are weak in that it is unlikely that the person is in the same state of mind as if they were actually accomplishing the task for their job or other real-world scenario.

\section{Surveys}

Naturalistic studies (e.g., studying people in their natural setting engaged in their real activities) are strong in their ecological validity yet take a considerable amount of time and number of subjects to do well. Several flow researchers instead resort to using surveys to study flow [Ghani and Deshpande, 1994; Novak et al., 2000; Trevino and Webster, 1992]. Whether Web or print based, these surveys use questionnaires with Likert-type scales and measure general experiences. They are limited in that they typically use closed-ended questions, and more importantly, in that respondents are asked to rate factors according to the general case, not regarding a specific experience. Surveying non-situated, generalized factors does not account for the dynamism of each factor and how its fluctuation influences flow. For example, a respondent's rating of $I$ am extremely skilled at using the Web [Novak et al., 2000] simplifies the delicate balance of challenges and skills that contribute to flow at a given time. Flow experiences on the Web are situational [Chen et al., 1999]. The challenges and skills required are not 
necessarily limited to the hardware and software. When users experience flow while communicating with a discussion group, it is often not the medium of the Web but the content of the discussion that yields an optimal experience. Thus, the challenges an individual experiences and the skills s/he uses are different depending on the Web activity.

Surveys, such as Chen et al. [1999], may be designed to situate a respondent in a particular flow experience. The reliability can be problematic because the respondent must recall the situation and distortion may occur. Recent empirical work [Pearce et al., In Press] shows evidence of the dynamic nature of flow as students are engaged in an online learning exercise. Pearce and colleagues find a recency effect when subjects are asked about their overall flow state.

Real time elicitation and multiple data points for each of the respondents will enable researchers to understand the actual experience of flow (not a recall of it) and how an individual's state changes. Of course, with real time elicitation, the timing is especially challenging because the researcher would not want to interrupt the flow state but instead want the respondent respond after the optimal state has subsided.

One-time surveys are limited further in that they are static for each individual. These surveys do not account for the dynamic nature of flow within each individual. A particular respondent may be biased toward ranking flow factors high. Only by viewing multiple points by an individual can we understand the dynamism and complexity of the flow experience. Methods like ESM that collect multiple data points for each individual provide a richer data set and enable the researcher to study the flow experience in different contexts. These contexts enhance the researcher's understanding of the flow experience.

\section{Qualitative Techniques}

Though event-contingent ESM may seem most valid, it is quite cumbersome for subjects and expensive for researchers. A middle-ground solution that has been gaining recognition for studying flow within $\mathrm{CME}$ is using qualitative techniques. We think qualitative techniques will enhance our understanding of flow by enabling us to investigate the "why" question, for example, why users prefer e-mail over voice mail [Trevino and Webster, 1992]. Examples of qualitative research for studying flow and the Web are rather sparse, but gaining momentum. Chen et al. [1999] use open-ended questionnaires and content analysis to explore the factors associated with flow while using the Web, perceived challenges and controls, and feelings associated with the experience. An article comparing goal-directed and experiential behavior on the Web uses qualitative techniques [Novak et al., 2003]. Two recent studies entail using semi-structured interviews to elicit flow experiences from users [Pace, 2004; Pilke, 2004]. Although these two inductive studies generally do not consider the theoretical work to date, and do not contribute new theory, we may be able to learn from their methods. Enabling respondents to use their own words to describe their experiences can ensure validity and uncover deeper aspects of the flow model within CME. Though the data is not collected in real time, it is situated in a particular time and place that is a natural situation for the respondent, not a fictitious one.

\section{CONCLUSION}

Despite the strong interest in adapting the phenomenon of flow to computer users over more than a decade, the literature shows inconsistencies and discrepancies. Few studies attempt to provide a coherent picture of the area. As evidenced by the existing studies on flow within CME, we must extend the seemingly very useful flow model in psychology to fit the rather complex computer mediated environment appropriately. The challenges for researchers are two-fold:

- conceptualizing or re-conceptualizing flow in CME and

- the operationalization and data collection for empirical studies. 
The diverse flow models demonstrate the different understandings of antecedents, flow experiences, and consequences. The major constructs of flow in CME need to be defined carefully.

A primary difference between the flow phenomenon in original psychology studies and the flow phenomenon in CME is the realization of a third component, which is neither the task, nor the person experiencing the flow. This third component, typically a type of ICT or artifact, accompanies the task a person is completing. By clearly distinguishing this third component from the task and being aware of the complexity it adds, we can gain a better understanding of the flow phenomenon within CME [Finneran and Zhang, 2003]. This important first step will help establish valid and reliable measures for the relevant constructs.

Individual differences include both traits and states, each having an influence when interacting with ICTs [Agarwal and Karahanna, 2000; Yager et al., 1997]. Individual differences, which are shown to be important in early non computer-mediated flow studies, are probably even more important in CME. Finneran and Zhang [2003] propose an abstract flow model that includes both the traits and state of an individual. Empirical research is much needed to validate or clarify which individual factors influence the flow experience and where they occur in the process.

Operationalizing the constructs and collecting data are difficult to perform rigorously. Naturalistic studies are gaining in prominence [Chen, 2000; Chen et al., 1999; Novak et al., 2003]; they provide examples on how flow can be studied in a specific context. More work and more research attention are needed in this direction, especially from methodologists.

Researchers had the foresight to use flow theory as a way to understand human behavior with computers and thus inform better ICT design, training and use. Their studies indicate the great promise that flow can yield in increased learning, improved attitudes, increased computer use, and overall, positive experiences within a computer-mediated environment. The benefits of flow experiences are clear. If we can clarify our thinking and improve our methods for studying flow, we will certainly gain better understanding on how to design effective human computer interactions that are conducive to these optimal experiences.

Editor's Note: This article was received on May 25, 2004 and was fully refereed. It was with the authors for approximately 4 months for 1 revision and was published on January _ 2005.

\section{REFERENCES}

Agarwal, R. and E. Karahanna (2000) "Time Flies When You're Having Fun: Cognitive Absorption and Beliefs about Information Technology Usage," MIS Quarterly (24)4, pp 665-694.

Atkinson, M. and C. Kydd (1997) "Individual Characteristics Associated with World Wide Web Use: An Empirical Study of Playfulness and Motivation," Data Base for Advances in Information Systems (28)2, pp 53-62.

Chen, H. (2000) "Exploring Web Users' On-line Optimal Flow Experiences," Unpublished PhD Dissertation, School of Information Studies, Syracuse, NY: Syracuse University.

Chen, H. and M.S. Nilan (1998) "An Exploration of Web Users' Internal Experiences: Application of the Experience Sampling Method to the Web environment," Proceedings of WebNet 98 -- World Conference of the WWW, Internet, and Intranet, Orlando, FL.

Chen, H., R. Wigand, and M.S. Nilan (1999) "Optimal Experience of Web Activities," Computers in Human Behavior (15)5, pp 585-608.

Chung, J. and F.B. Tan (2004) "Antecedents of Perceived Playfulness: An Exploratory Study on User Acceptance of General Information-Searching Websites," Information \& Management (41)7, pp 869-881.

Clarke, S.G. and J.T. Haworth (1994) '"Flow' Experience in Daily Lives of Sixth-Form College Students," British Journal of Psychology (85), pp 511-523. 
Csikszentmihalyi, M. (1975) Beyond Boredom and Anxiety, San Francisco, CA: Jossey-Bass.

Csikszentmihalyi, M. (1988) "The Flow Experience and Human Psychology," in Csikszentmihalyi, M. and Csikszentmihalyi, I.S. (Eds.), Optimal Experience: Psychological Studies of Flow in Consciousness, New York: Cambridge University Press, pp. 15-35.

Csikszentmihalyi, M. (1990) Flow: The Psychology of Optimal Experience, New York: Harpers Perennial.

Csikszentmihalyi, M. and I.S. Csikszentmihalyi (Eds.) (1988) Optimal Experience: Psychological Studies of Flow in Consciousness. New York: Cambridge University Press.

Csikszentmihalyi, M. and R. Larson (1992) "Validity and Reliability of the Experience Sampling Method," in de Vries, M.W.(Ed.), The Experience of Psychopathology: Investigating Mental Disorders in their Natural Settings, New York: Cambridge University Press, pp 4357.

Csikszentmihalyi, M., R. Larson, and S. Prescott (1977) "The Ecology of Adolescent Experience," Journal of Youth and Adolescence (6), pp 281-294.

Daft, R.L. and R.H. Lengel (1986) "Organizational Information Requirements, Media Richness and Structural Design," Management Science (32)5, pp 554-571.

Dervin, B., T.L. Jacobson, and M.S. Nilan (1982) "Measuring Aspects of Information Seeking: A Test of Quantitative/Qualitative Methodology," Communication Yearbook (6), pp 416-444.

Ellis, G.D., J.E. Voelkl, and C. Morris (1994) "Measurement and Analysis Issues with Explanation of Variance in Daily Experiences Using the Flow Model," Journal of Leisure Research (26)4, pp 337-356.

Finneran, C.M. and P. Zhang (2003) "A Person-Artefact-Task (PAT) Model of Flow Antecedents in Computer-Mediated Environments," International Journal of Human-Computer Studies (59)4, pp 475-496.

Ghani, J. (1995) "Flow in Human Computer Interactions: Test of a Model," in Carey, J. (Ed.), Human Factors in Information Systems: Emerging Theoretical Bases, New Jersey: Ablex Publishing Corp, pp 291-311.

Ghani, J.A. and S.P. Deshpande (1994) "Task Characteristics and the Experience of Optimal Flow in Human-Computer Interaction," The Journal of Psychology (128)4, pp 381-391.

Ghani, J.A., R. Supnick, and P. Rooney (1991) "The Experience of Flow in Computer-Mediated and in Face-To-Face Groups," Proceedings of the Twelfth International Conference on Information Systems, New York, NY.

Griffith, D.A., R.F. Krampf, and J.W. Palmer (2001) "The Role of Interface in Electronic Commerce: Consumer Involvement with Print Versus On-Line Catalogs," International Journal of Electronic Commerce (5)4, pp 135-153.

Guru, A. and F. Nah (2001) "Effect of Hypertext and Animation on Learning," in Dasgupta, S. (Ed.), Managing Internet and Intranet Technologies in Organizations Idea Publishing Group, pp 50-61.

Hamilton, A.J., R.J. Haier, and M.S. Buchsbaum (1984) "Intrinsic Enjoyment and Boredom Coping Scales: Validation With Personality, Evoked Potential and Attention Measures," Personality and Individual Differences (5)2, pp 183-193.

Haworth, J. and S. Evans (1995) "Challenge, Skill and Positive Subjective Status in the Daily Life of a Sample of YTS Students," Journal of Occupational and Organizational Psychology (68), pp 109-121.

Hoffman, D.L. and T.P. Novak (1996) "Marketing in Hypermedia Computer-Mediated Environments: Conceptual Foundations," Journal of Marketing (60) July, pp 50-68. 
Hsu, C.-L. and H.-P. Lu (2004) "Why Do People Play On-Line Games? An Extended TAM with Social Influences and Flow Experience," Information \& Management (41)7, pp 853-868.

Huang, M.-H. (2003) "Designing Website Attributes To Induce Experiential Encounters," Computers in Human Behavior (19)4, pp 425-442.

Koufaris, M. (2002) "Applying the Technology Acceptance Model and Flow Theory to Online Consumer Behavior," Information Systems Research (13)2, pp 205-223.

Larson, R. (1988) "Flow and Writing," in Csikszentmihalyi, M. and Csikszentmihalyi, I.S. (Eds.), Optimal Experience: Psychological Studies of Flow in Consciousness, New York: Cambridge University Press, pp. 150-171.

Larson, R. and P.A.E.G. Delespaul (1992) "Analyzing Experience Sampling Data: A Guidebook for The Perplexed," in Devries, M.W. (Ed.), The Experience of Psychopathology: Investigating Mental Disorders in their Natural Settings, New York: Cambridge University Press, pp. 58-78.

Lieberman, J.N. (1977) Playfulness, New York: Academic Press.

Malone, T.W. (1981) "Toward A Theory of Intrinsically Motivating Instruction," Cognitive Science (4), pp 333-369.

Martocchio, J.J. and J. Webster (1992) "Effects of Feedback and Cognitive Playfulness on Performance in Microcomputer Software Training," Personnel Psychology (45)3, pp 553578.

Massimini, F. and M. Carli (1988) "The Systematic Assessment of Flow in Daily Experience," in Csikszentmihalyi, M. and Csikszentmihalyi, I.S. (Eds.), Optimal Experience: Psychological Studies of Flow in Consciousness, New York: Cambridge University Press, pp. 266-287.

Nel, D., R.V. Niekerk, J.-P. Berthon, and T. Davies (1999) "Going with the Flow: Web Sites and Customer Involvement," Internet Research: Electronic Networking Applications and Policy (9)2, pp 109-116.

Newby, G.B., M.S. Nilan, and L.M. Duvall (1991) "Toward A Reassessment of Individual Differences in Information Systems: The Power of User-Based Situational Predictors," Proceedings of the American Society for Information Science (ASIS) 54th Annual Meeting, October 27-31, 1991, Washington, DC, pp 73-81.

Novak, T.P., D.L. Hoffman, and A. Duhachek (2003) "The Influence of Goal-Directed and Experiential Activities on Online Flow Experiences," Journal of Consumer Psychology (13)1-2, pp 3-16.

Novak, T.P., D.L. Hoffman, and Y.-F. Yung (2000) "Measuring the Customer Experience in Online Environments: A Structural Modeling Approach," Marketing Science (19)1, pp 2242.

Pace, S. (2004) "A Grounded Theory of the Flow Experiences of Web Users," International Journal of Human-Computer Studies (60)3, pp 327-363.

Pearce, J.M., M. Ainley, and S. Howard (in Press) "The Ebb and Flow of Online Learning," Computers in Human Behavior.

Pilke, E.M. (2004) "Flow Experiences in Information Technology Use," International Journal of Human-Computer Studies (61)3, pp 347-357.

Shim, S., M.A. Eastlick, S.L. Lotz, and P. Warrington (2001) "An Online Prepurchase Intentions Model: The Role of Intention to Search," Journal of Retailing (77)3, pp 397-416.

Skadberg, Y.X. and J.R. Kimmel (2004) "Visitors' Flow Experience while Browsing a Web Site: Its Measurement, Contributing Factors and Consequences," Computers in Human Behavior (20), pp 403-422. 
Steuer, J. (1991) "Defining Virtual Reality: Dimensions Determining Telepresence," Journal of Communication (42)4, pp 73-93.

Trevino, L.K. and J. Webster (1992) "Flow in Computer-Mediated Communication," Communication Research (19)5, pp 539-573.

Webster, J. "Playfulness and Computers At Work," Unpublished PhD Dissertation, New York University, New York, 1989.

Webster, J. and H. Ho (1997) "Audience Engagement in Multimedia Presentations," The Data Base Advances in Information Systems (28)2, pp 63-77.

Webster, J., L.K. Trevino, and L. Ryan (1993) "The Dimensionality and Correlates of Flow in Human-Computer Interaction," Computers in Human Behavior (9), pp 411-426.

Wheeler, L. and H.T. Reis (1991) "Self-Recording of Everyday Life Events: Origins, Types, and Uses," Journal of Personality (59)3, pp 339-354.

Yager, S.E., L.A. Kappelman, G.A. Maples, and V.R. Prybutok (1997) "Microcomputer Playfulness: Stable or Dynamic Trait?" The Data Base for Advances in Information Systems (28)2, pp 43-52.

\section{LIST OF ABBREVIATIONS}

$\begin{array}{ll}\text { CME } & \text { Computer Mediated Environment } \\ \text { ESM } & \text { Experience Sampling Method } \\ \text { ICT } & \text { Information and Communication Technologies } \\ \text { OSL } & \text { Optimum Stimulation Level } \\ \text { PAT } & \text { Person-Artifact-Task Model }\end{array}$

\section{ABOUT THE AUTHORS}

Christina M. Finneran is a Ph.D. Candidate at Syracuse University School of Information Studies. She received her masters in geographic information systems (GIS) from the State University of New York at Buffalo and her bachelor's degree from Cornell University. Her research interests are human-computer interaction, personal digital libraries, and technologyenhanced education.

Ping Zhang is Associate Professor at School of Information Studies, Syracuse University. She earned her Ph.D. in Information Systems from The University of Texas at Austin. She teaches Human-Computer Interaction, Systems Analysis and Design, Database Management Systems, and other IT related topics. Her research appears or will appear in journals such as Behaviour \& Information Technology, Communications of ACM, Communications of AIS, Computers in Human Behavior, Decision Support Systems, International Journal of Human-Computer Studies, International Journal of Electronic Commerce, Journal of American Society for Information Science and Technology, Journal of AIS, IEEE Computer Graphics and Applications, among others. Dr. Zhang received three Best Paper awards at various international IS conferences, and an excellence in teaching award from The University of Texas at Austin (1994). She is an Associate Editor for IJHCS and a guest editor for special issues of JAIS, JMIS, IJHCS, IJHCl, and BIT. Dr. Zhang is the founding chair (2001-2004) of the AIS Special Interest Group on $\mathrm{HCl}$ (SIGHCl).

Copyright $\odot 2005$ by the Association for Information Systems. Permission to make digital or hard copies of all or part of this work for personal or classroom use is granted without fee provided that copies are not made or distributed for profit or commercial advantage and that copies bear this notice and full citation on the first page. Copyright for components of this work owned by others than the Association for Information Systems must be honored. Abstracting with credit is permitted. To copy otherwise, to republish, to post on servers, or to redistribute to lists requires prior specific permission and/or fee. Request permission to publish from: AIS Administrative Office, P.O. Box 2712 Atlanta, GA, 30301-2712 Attn: Reprints or via e-mail from ais@aisnet.org 


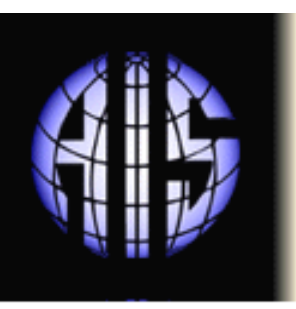

\title{
ommunications of the A ssociation for Information $N_{y s t e m s}$
}

\section{EDITOR-IN-CHIEF}

ISSN: 1529-3181

\author{
Paul Gray
}

Claremont Graduate University

AIS SENIOR EDITORIAL BOARD

\begin{tabular}{|l|l|l|}
\hline Detmar Straub & Paul Gray & Sirkka Jarvenpaa \\
Vice President Publications & Editor, CAIS & Editor, JAIS \\
Georgia State University & Claremont Graduate University & University of Texas at Austin \\
\hline Edward A. Stohr & Blake Ives & Reagan Ramsower \\
Editor-at-Large & Editor, Electronic Publications & Editor, ISWorld Net \\
Stevens Inst. of Technology & University of Houston & Baylor University \\
\hline
\end{tabular}

\section{CAIS ADVISORY BOARD}

\begin{tabular}{|c|c|c|c|}
\hline $\begin{array}{l}\text { Gordon Davis } \\
\text { University of Minnesota }\end{array}$ & $\begin{array}{l}\text { Ken Kraemer } \\
\text { Univ. of Calif. at Irvine }\end{array}$ & $\begin{array}{l}\text { M.Lynne Markus } \\
\text { Bentley College }\end{array}$ & $\begin{array}{l}\text { Richard Mason } \\
\text { Southern Methodist Univ. }\end{array}$ \\
\hline $\begin{array}{l}\text { Jay Nunamaker } \\
\text { University of Arizona }\end{array}$ & $\begin{array}{l}\text { Henk Sol } \\
\text { Delft University }\end{array}$ & $\begin{array}{l}\text { Ralph Sprague } \\
\text { University of Hawaii }\end{array}$ & $\begin{array}{l}\text { Hugh J. Watson } \\
\text { University of Georgia }\end{array}$ \\
\hline \multicolumn{4}{|c|}{ CAIS SENIOR EDITORS } \\
\hline $\begin{array}{l}\text { Steve Alter } \\
\text { U. of San Francisco }\end{array}$ & $\begin{array}{l}\text { Chris Holland } \\
\text { Manchester Bus. School }\end{array}$ & $\begin{array}{l}\text { Jaak Jurison } \\
\text { Fordham University }\end{array}$ & $\begin{array}{l}\text { Jerry Luftman } \\
\text { Stevens Inst.of Technology }\end{array}$ \\
\hline \multicolumn{4}{|c|}{ CAIS EDITORIAL BOARD } \\
\hline $\begin{array}{l}\text { Tung Bui } \\
\text { University of Hawaii }\end{array}$ & $\begin{array}{l}\text { Fred Davis } \\
\text { U.ofArkansas, Fayetteville }\end{array}$ & $\begin{array}{l}\text { Candace Deans } \\
\text { University of Richmond }\end{array}$ & $\begin{array}{l}\text { Donna Dufner } \\
\text { U.of Nebraska -Omaha }\end{array}$ \\
\hline $\begin{array}{l}\text { Omar El Sawy } \\
\text { Univ. of Southern Calif. }\end{array}$ & $\begin{array}{l}\text { Ali Farhoomand } \\
\text { University of Hong Kong }\end{array}$ & $\begin{array}{l}\text { Jane Fedorowicz } \\
\text { Bentley College }\end{array}$ & $\begin{array}{l}\text { Brent Gallupe } \\
\text { Queens University }\end{array}$ \\
\hline $\begin{array}{l}\text { Robert L. Glass } \\
\text { Computing Trends }\end{array}$ & $\begin{array}{l}\text { Sy Goodman } \\
\text { Ga. Inst. of Technology }\end{array}$ & $\begin{array}{l}\text { Joze Gricar } \\
\text { University of Maribor }\end{array}$ & $\begin{array}{l}\text { Ake Gronlund } \\
\text { University of Umea, }\end{array}$ \\
\hline $\begin{array}{l}\text { Ruth Guthrie } \\
\text { California State Univ. }\end{array}$ & $\begin{array}{l}\text { Alan Hevner } \\
\text { Univ. of South Florida }\end{array}$ & $\begin{array}{l}\text { Juhani livari } \\
\text { Univ. of Oulu }\end{array}$ & $\begin{array}{l}\text { Claudia Loebbecke } \\
\text { University of Cologne }\end{array}$ \\
\hline $\begin{array}{l}\text { Sal March } \\
\text { Vanderbilt University }\end{array}$ & $\begin{array}{l}\text { Don McCubbrey } \\
\text { University of Denver }\end{array}$ & $\begin{array}{l}\text { Emannuel Monod } \\
\text { University of Nantes }\end{array}$ & $\begin{array}{l}\text { Michael Myers } \\
\text { University of Auckland }\end{array}$ \\
\hline $\begin{array}{l}\text { Seev Neumann } \\
\text { Tel Aviv University }\end{array}$ & $\begin{array}{l}\text { Dan Power } \\
\text { University of No. Iowa }\end{array}$ & $\begin{array}{l}\text { Ram Ramesh } \\
\text { SUNY-Buffalo }\end{array}$ & $\begin{array}{l}\text { Kelley Rainer } \\
\text { Auburn University }\end{array}$ \\
\hline $\begin{array}{l}\text { Paul Tallon } \\
\text { Boston College }\end{array}$ & $\begin{array}{l}\text { Thompson Teo } \\
\text { Natl. U. of Singapore }\end{array}$ & $\begin{array}{l}\text { Doug Vogel } \\
\text { City Univ. of Hong Kong }\end{array}$ & $\begin{array}{l}\text { Rolf Wigand } \\
\text { Uof Arkansas, LittleRock }\end{array}$ \\
\hline $\begin{array}{l}\text { Upkar Varshney } \\
\text { Georgia State Univ. }\end{array}$ & $\begin{array}{l}\text { Vance Wilson } \\
\text { U.Wisconsin,Milwaukee }\end{array}$ & $\begin{array}{l}\text { Peter Wolcott } \\
\text { U. of Nebraska-Omaha }\end{array}$ & \\
\hline
\end{tabular}

\section{DEPARTMENTS}

Global Diffusion of the Internet.

Editors: Peter Wolcott and Sy Goodman

Papers in French

Editor: Emmanuel Monod

Information Technology and Systems.

Editors: Alan Hevner and Sal March

Information Systems and Healthcare

Editor: Vance Wilson

\section{ADMINISTRATIVE PERSONNEL}

\begin{tabular}{|l|l}
\hline Eph McLean & Reagan Ramsower \\
AIS, Executive Director & Publisher, CAIS \\
Georgia State University & Baylor University \\
\hline
\end{tabular}

